\section{LIBRI}

www.libridergi.org

Kitap Tanıtımı, Eleştiri ve Çeviri Dergisi

Journal of Book Notices, Reviews and Translations

Volume II (2016)

C. GATES, Antik Kentler: Antik Yakındoğu, Mısır, Yunan ve Roma'da Kentsel Yaşamın Arkeolojisi. İstanbul 2015. Koç Üniversitesi Yayınları, 605 sayfa (321 şekil ile birlikte). Çev. B. Cezar. ISBN: 9786055250522

\section{Çiğdem ÖNER}

Libri: Kitap Tanıtımı, Eleştiri ve Çeviri Dergisi'nde bulunan içeriklerin tümü kullanıcılara açık, serbestçe/ücretsiz 'açık erişimli' bir dergidir. Kullanıılar, yayıncıdan ve yazar(lar)dan izin almaksızın, dergideki kitap tanıtımı, eleştiri ve çevirileri tam metin olarak okuyabilir, indirebilir, dağıtabilir, çıktııını alabilir ve kaynak göstererek bağlantı verebilir.

Libri, uluslararası hakemli elektronik (online) bir dergi olup değerlendirme süreci biten kitap tanıtımı, eleştiri ve çeviriler derginin web sitesinde (www.libridergi.org) yıl boyunca ilgili sayının içinde (Volume II: Ocak-Aralık 2016) yayımlanır. Aralık ayı sonunda ilgili yıla ait sayı tamamlanır.

Dergide yayımlanan eserlerin sorumluluğu yazarlarına aittir.

Atıf Düzeni

Ç. Öner, Antik Kentler: Antik Yakındoğu, Mısır, Yunan ve Roma'da Kentsel Yaşamın Arkeolojisi. Yazar: C. Gates, Çeviren: B. Cezar. Libri II (2016) 497-501. DOI: 10.20480/lbr.2016042

Geliş Tarihi: 09.12.2016 | Kabul Tarihi: 21.12.2016 | Elektronik Yayın Tarihi: 26.12.2016

URL: http://dx.doi.org/10.20480/lbr.2016042

Editörya Phaselis Project

www.phaselis.org 


\title{
C. GATES, Antik Kentler: Antik Yakındoğu, Mısır, Yunan ve Roma'da Kentsel Yaşamın Arkeolojisi. İstanbul 2015. Koç Üniversitesi Yayınları, 605 sayfa (321 şekil ile birlikte). Çev. B. Cezar. ISBN: 9786055250522
}

\begin{abstract}
Çiğdem ÖNER*
Inceleme altına alınacak olan ve Antik Kentler: Antik Yakındoğu, Mısır, Yunan ve Roma'da Kentsel Yaşamın Arkeolojisi başlıklı bu çalışma, antik Yakındoğu, Mısır, Yunan ve Roma dünyalarının kentlerini, temel anlamda fiziksel görünüm, kentsel doku ve de bu yerleşimlerin kültürel ve tarihsel özellikleri perspektifinden değerlendirmektedir. Antik siteler, ana ve ara caddeler, kent meydanları ve kentsel yaşam alanları dışındaki diğer bölgeleri kapsayan binalar, yine bu yapıların kent teritoryumu özelindeki düzenleri ve antik toplumlardaki işlevlerini gösteren mimari unsurlar da kitaptaki kilit öğeleri oluşturmaktadır.

Bu bağlamda, Içindekiler (5-11) kısmı ile başlayan kitap, Şekil Listesi (13-23) ile devam etmektedir. Daha sonra gelen Önsöz (25-26) ve İkinci Basıma Önsöz (27-28) kısımlarındaysa, yazar antik Yakındoğu, Mısır, Hellas ve Roma'nın kent ve medeniyetlerini arkeolojik bir bakış açısıyla ele aldığını ve bu doğrultuda kentsel merkezleri odak noktası olarak belirlediğini aktarmaktadır. Bu kentsel merkezler incelenirken, mimari ve diğer maddi kalıntılar ile tarihsel ve sosyoekonomik koşulların buralarda yaşamış insanların deneyimlerinin özüne eşlik ettiği vurgusu yapılmaktadır. Yazar, bu kentsel merkezlerin izlerinin Yakındoğu'nun MÖ dokuzuncu ve altıncı binyıllarına kadar izlendiğinden ve yine bu izlerin MS dördüncü yüzyılın başlarına (paganlığın sonlarına) dek sürdüğünden, sonuç olarak da karmaşık ve oldukça renkli bir kültürler geçidinden bahsetmektedir. Akabinde, Sümerler ve Babilliler, Asurlar ve Mısırlılar, Minoslar ve Etrüskler, Hellenler ve de Romalılar gibi birbirlerinden olabildiğince farklı olan kültürlerin, yine de uzun bir karşılıklı bağlantılar zinciriyle birbirlerine bağıı olduklarından söz etmektedir.
\end{abstract}

Kronoloji (29-32) kısmında ise yazar, kitabın tüm içeriğini adeta özet bir tablo olarak bizlere sunmaktadır. Bu doğrultuda, kronolojik tabloya göz attığımızda, Kısım Bir'de (45-275) Yakındoğu ve Doğu Akdeniz kentleri: Neolitik, Tunç Çağı ve Demir Çağı'nın konu alındığı, Kısım Iki'de (277-405) ise Hellen kentlerine odaklanıldığı görülmektedir. Kısım Üç'te de (407-551), antik Italya ve Roma Imparatorluğu'ndaki kentler tarihsel bir sıra ve belirli şekillerle okuyuculara aktarılmaktadır.

Giriş (33-44) kısmında yazar, antik Yakındoğu, Mısır, Hellen ve Roma dünyalarının kentlerini, ağırlıklı olarak fiziksel görünüm, kentsel biçim ve bu kentlerin kültürel ve tarihsel bağlamları üzerinde durarak incelediğini belirtmekte ve bu incelemeleri yaparken de kilit unsurun mimari olduğu vurgusunu yapmaktadır. Kentin tanımı alt başlığında; kitabın ana konusunun kent olmasından yola

\footnotetext{
* MA., Akdeniz Üniversitesi, Akdeniz Uygarlıkları Araştırma Enstitüsü, Akdeniz Eskiçağ Araştırmaları Anabilim Dalı, Antalya.demrederin@gmail.com
} 
çıkarak, "kent" kelimesinin tanımını yapmakta ve kent kavramının demografik, coğrafi, toplumsal, ekonomik ve ideolojik yönlere sahip olduğunu belirtmektedir. Kent tanımında da, bilgi kaynakları, tarihlerin belirlenmesi (serileme, tabakalanma ve höyüklerin oluşumu, mutlak tarihler: radyo-karbon yöntemi, mutlak tarihler: Mısır ve Mezopotamya'da tarihsel kayıtlar) ve terminoloji hakkında yan başlıklarına yer vermektedir. Son olarak da, "antik isimlerin yazılısında Ana Britannica'nın temel alındığı notu düşülmektedir.

Kitabın içeriği üç ana kısımda toplanmaktadır, bu kısımlardan kısım bir, on bir bölüm, kısım iki ve kısım üç de, yedişer bölüm altında detaylandırılmaktadır. Kısım Bir Yakındoğu ve Doğu Akdeniz Kentleri: Neolitik, Tunç ve Demir Çağı (45-275) başlı̆ını taşımaktadır. Birinci kısmın ilk bölümü olan Neolitik Çağda Yakındoğu'daki Kasaba ve Köyler'de (47-65), Üst Paleolitik ve Mezolitik dönemler (ca. MÖ 35000 - 8550), Yakındoğu'da Neolitik Dönem (ca. MÖ 8550 - 5000) ve Halaf ve Obeyt dönemleri (ca. MÖ 5000 - 3500) incelenmektedir. Ayrıca bu bölümde, ilk önce antik Yakındoğu'nun fiziksel dünyası ile neolitik gıda üretimini ve bunun insan yerleşimi için anlamını ele aldıktan sonra, Filistin'deki Jeriko ve Türkiye'deki Çayönü, Çatalhöyük ve Göbekli Tepe'yi incelemektedir.

îkinci bölüm, Erken Sümer Kentleri (67-92) olarak isimlendirilmektedir. Burada, Obeyt Dönemi (ca. MÖ 5000 - 3500), Protoliterate (Uruk) Dönemi (ca. MÖ 3500 - 2900) ve Erken Hanedanlar Dönemi (ca. MÖ 2900 - 2350) incelenmektedir. Bu doğrultuda, Yakındoğu ve Akdeniz havzasındaki ilk kentlerin Güney Mezopotamya'da yaşamış olan ve Sümerler adı verilen bir halk tarafından kurulduğu belirtilmektedir. Yazar, erken Sümer kentlerini inceleyerek, onların MÖ dördüncü binyıl içinde yazıyı keşfettikleri vurgusunu yapmakta ve Sümerleri buna iten etmenlerin neler olduğu konusunda bilgi vermektedir.

Üçüncü bölüm, Mezopotamya Kentleri: MÖ Üçüncü Binyıl Sonları ve ikinci Binyıl (93-110) başlığını taşımaktadır. Yazar burada, Akadlar (ca. MÖ 2350 - 2150), Gutiler (ca. MÖ 2150 - 2000) ve Sümerler (ikinci egemenlik dönemi) gibi Mezopotamya tarihi açısından önem arz eden başat güçleri ele almaktadır. Akabinde, Yeni Sümer (ca. MÖ 2125 - 2000), Lagaşı Gudea ve de Ur III (üçüncü Ur Hanedanı: ca. MÖ 2100 - 2000), Eski Babil (ca. MÖ 2000 - 1530) ve İsin - Larsa (ca. MÖ 2000 1760) dönemleri üzerine bilgilendirmede bulunmaktadır. Son olarak, Birinci Babil Hanedanı (ca. MÖ 1830 - 1531), Babilli Hamurabi (ca. MÖ 1728 - 1686) ve de Kassitler (ca. MÖ 1530 - 1150) gibi Mezopotamya kökenli güç odaklarını incelemektedir. Sonuç olarak yazar bu dönemin, Sümer şehir-devlet kavramının, devletlerin, hatta imparatorlukların kurulmasıyla tehdit edildiğini aktarmakta ve Akadlar ile Üçüncü Ur Hanedanı́nın daha büyük ve daha kapsamlı siyasal birimleri ortaya çıkaran ve de önemli siyasal değişimleri yaratan güçler olduğunu vurgulamaktadır.

Dördüncü bölüm ise Indus Vadisi Medeniyeti'nin Kentleri (111-122) başlığını taşımaktadır. Burada, İndus Vadisi medeniyeti ve de Harappa veya Olgunluk evresi (ca. MÖ 2600 - 1900) hakkında bilgi paylaşımı yapılmaktadır. Ayrıca yazar, İndus Vadisi medeniyetinin (ya da önemli kentlerinden birinin adıyla Harappa'nın), MÖ III. binyılda Kuzey Afrika ve Güneybatı Asya'daki üç büyük ırmak temelli medeniyetin ikincisi olduğunu ve de mimari kent planlaması açısından kendilerine özgü tercihlerinin bulunduğunu belirtmektedir. Bu durumdan dolayı da, Mezopotamya ve Mısır kentleri arasında karşılaştırmalar yapmaktadır. Ayrıca Harappa kazı alanlarından bahsederek, en önemlisi olan Mohenco - Daro üzerine odaklanmaktadır. Son olarak, Harappa Bölgesi'nin en güneydoğu ucundaki küçük Lothal kentine de değinilmekte, bu bağlamda bir taşra kasabasının plan ve mimari özellikleri bir metropolle karşılaştııımaktadır.

Beşinci bölüm Piramitler Ülkesi Mısır (123-147) başlığını taşımaktadır. Burada Mısır’ın hanedan- 
Iık dönemleri kronolojik bir perspektifte incelenmektedir. Altıncı bölüm, MÖ ikinci Binyıl'da Mısır Kentleri, Tapınakları ve Mezarları (149-172) başlığını taşımaktadır. Burada Mısır’ın Orta Kralık: 11 ve 12. Hanedanlar Dönemi (ca. MÖ 2060 - 1795) ve İkinci Ara Dönem: 13- 17. Hanedanlar Süreci (ca. MÖ 1795 - 1550) incelenmektedir. Ayrıca, Yeni Krallık: (ca. MÖ 1550 - 1070 ), 18. Hanedan: (ca. MÖ 1550 - 1295), 19. Hanedan: (ca. MÖ 1295 - 1186), 20. Hanedan: (ca. MÖ 1186 - 1070), Üçüncü Ara Dönem: 21'inciden 24. Hanedana (ca. MÖ 1070 - 715), Geç Dönem: 25'inciden 30. Hanedana, íkinci Pers İşgali (MÖ 760 - 332) ve Büyük İskender'in Mısır'ı Fethi: (MÖ 332) gibi farklı tarihsel süreçler ele alınmaktadır.

Yedinci Bölüm Ege'deki Tunç Çağı Kasaba ve Kentleri (173-196) başlığını taşımaktadır. Burada, Ege medeniyetleri ve kentleri ele alınmaktadır. Anadolu'da Tunç Çağı Kentleri (197-214) başlıkı sekizinci bölümdeyse, Troia ve Hattuşa gibi önde gelen Tunç Çağı kentlerine değinilmektedir. Yazar ilk olarak ca. MÖ 2900 - 1100 yılları arasında etkili olan Troia kentinin katmanlarını değerlendirmektedir. Bu bağlamda, Troia kentlerini de Troia I, II, III-V, VI, VIla, VIIIb 1 ve VIIb 2 alt başlıklarında detaylandırmaktadır. Diğer alt başlık olan Hattuşa'da da, Hititler ele alınmakta ve ca. MÖ 1575 1400 yılları arasında Eski Hitit Krallığı, ca. MÖ 1400 - 1350 yılları arasında Orta Hitit Krallığı ve ca. MÖ 1350 - 1200 yılları arasındaki Hitit İmparatorluğu mercek altına alınmaktadır.

Dokuzuncu bölüm, Geç Tunç Çağında Kıbrılılar, Kenanlılar ve Levant Ticaret Kentleri (215 - 231) başlığına sahiptir. Bu bağlamda, Kıbrıslılar ile ilgili araştırmalar yapıııken, ca. MÖ 1650 - 1050 yılları arasındaki Geç Tunç Çağı (Geç Kıbrıs) Dönemi detaylandırılmakta ve bu dönem Geç Kıbrıs I, II ve III şeklinde sınıflandırılmaktadır. MÖ XIV - XIII. yüzyıllarda etkin bir konuma ulaşmış olan Ugarit'in gelişme dönemi, kentin ca. MÖ 1190 - 1180 yıllarındaki yıkımlarına kadar incelenmektedir. Ayrıca MÖ XIV. yüzyıl sonlarına tarihlendirilen Uluburun Batığı ve de ca. MÖ 1220 yıllarında batmış olduğu düşünülen Gelidonya Burnu Batığı hakkında bilgi aktarılmaktadır

Demir Çağında Yakındoğu Kentleri (233-258) başıkılı onuncu bölümde, MÖ XI. yüzyıl ile MÖ 330 yııı arasındaki dönem mercek altına alınmaktadır. Akabinde, ca. MÖ 1000 - 612 yılları arasında varlık gösteren Yeni Asur İmparatorluğu ve de MÖ 612 - 539 yılları arasında hüküm süren Yeni Babil Imparatorluğu hakkında değerlendirmede bulunulmaktadır. Sonrasında, MÖ XIV-XI. yüzyıllar arasında varlık gösteren Frigler ve MÖ IX-VII. yüzyıllar arası hükmünü sürdüren Urartular özelinde Anadolu incelenmektedir. Ayrıca yazar Levant kentlerini Fenikeliler, Filistiler ve ibraniler olmak üzere üç alt başı̆̆a ayırmaktadır. Bu alt başlıkları detaylandırırken, en önemli kentlerinden biri Tyros (Tsor/Sur) olan Fenikelilerden başlamaktadır. Daha sonra Sidon (Sayda) ve Byblos (Gebal) kentlerini incelemektedir. Bölüm 10'un son kısmı, Perslere ayrılmaktadır. Persler de, MÖ VIII. yüzyıldan MÖ 550'ye kadar aktif olan Medler ve de MÖ 550 - 330 yılları arasında aktif olan Akhamendler alt başlıklarında detaylandırılmaktadır.

Birinci kısmın son ve on birinci alt başlığı Fenike ve Kartaca Kentleri (259-275) olarak isimlendirilmektedir. Burada, Fenikelilerin en önde gelen kentleri olan, Tyros (Tsor/Sur), Sidon (Sayda), BybIos (Gebal), Beyrut (Beerot) ve Arvad kentleri detaylı olarak incelenmektedir. Akabinde, Tyros'tan gelen Fenikelilerce MÖ 814'te (geleneksel tarih) kurulan Kartaca ve ona bağlı koloni kentleri ve uygarlı̆ın genel tarihçesi kronolojik olarak anlatılmaktadır.

Kısım iki ise Yunan Kentleri (277 - 405) başlığına sahiptir. Bu kısmın ilk ve kitabın da on ikinci bölümü, Demir Çağında IIlk Yunan Şehir-Devletleri (MÖ On Birinci - Yedinci Yüzyıllar Arası) (279-296) olarak isimlendirilmektedir. Bu bölüm incelenirken, Antik Yunan'ın kültürel dönemleri kronolojik alt başlıklar şeklinde değerlendirme altına alınmaktadır. Arkaik Yunan Kentleri, I (297-308) olarak isim- 
lendirilen on üçüncü bölümde, Hellen mimarisinin önemli yapısal düzenlerinden Dor ve Ion tarzları, erken Dor tarzı tapınaklar (örneğin: Thermon, Olimpia, Kerkia) ve erken Ion tarzı tapınaklar (örneğin: Sisam ve de Ephesos) özelinde detaylı bir şekilde incelenmektedir. Daha sonra, MÖ VI. yüzyılda Hellen medeniyetinin en canlı merkezlerinin odak noktası olan Doğu Hellen kentleri ele alınmaktadır. On dördüncü bölüm, Arkaik Yunan Kentleri, II ( 309-320) kapsamında ise, MÖ V. yüzyılın ikinci çeyreğinde süper güç olarak sivrilen Sparta ve Atina kentleri oldukça detaylı bir şekilde incelenmektedir.

Yunan Temenosları (321-338) başlıklı on beşinci bölümde, Hellen kültüründe önemli yer tutan dini merkezlerden, yani temenoslardan olan Delphoi'deki Apollon ve Olimpia'daki Zeus temenosları detaylı bir şekilde anlatılmaktadır. MÖ Beşinci Yüzyılda Atina (339-359) başı|ılı on altıncı bölümde, anlatım iki alt başıkta toplanmaktadır. İlk alt başlık ca. MÖ 480 - 450 yılları arasındaki Erken Klasik Dönem'i kapsarken, diğeri ise ca. MÖ 450 - 400 yılları arasındaki Yüksek Klasik Dönem'i içermektedir. Geç Klasik Dönemde Yunan Kentleri ve Temenosları (361-380) başlıklı on yedinci bölüm, ca. MÖ 400 - 323 yılları arasını kapsamaktadır. Yazar burada, Epidauros'daki tiyatroyu, Asklepios Temenos'unu, Piriene ve Olynthos'taki kent planlarını ve evleri ve de Vergina (antik Aigai) ile Halikarnasos'taki kral mezarlarını inceleme altına almaktadır. Helenistik Kentler (381-405) başlıklı on sekizinci bölümdeyse, Büyük İskender'in ölümü (MÖ 323), III. Attalos'un Pergamon'u Roma'ya miras bırakışı (MÖ 133) ve Aktium Savaşı (MÖ 31) alt başlıkları özelinde Helenistik Dönem ile alakalı bazı temalar ve bu olayların kentlere etkileri örneklerle anlatılmaktadır.

Kısım Üç Antik italya ve Roma Imparatorluğu'nda Kentler (407-551) olarak isimlendirilmektedir. Bu kısmın ilk ve kitabın da on dokuzuncu bölümü, Italya'daki Yunan ve Etrüsk Kentleri (409-432) başlığını taşımaktadır. Yazar burada, Güney İtalya ve Sicilya'daki Hellen yerleşimlerini (MÖ VIII-III. yüzyıl arası), Syrakusai'ın Romalılarca fethini (MÖ 212) ve Etrüskleri (MÖ VIII-II. yüzyıllar arası) incelenmektedir. Roma: Doğuşundan Cumhuriyet'in Sonuna (433-456) başlıklı yirminci bölümde, Roma tarihinin krallık ve cumhuriyet dönemleri değerlendirilmektedir. Bu bağlamda Roma'nın geleneksel kuruluş tarihi olan, MÖ 21 Nisan 753'ten başlanılarak, Roma'daki Etrüsk egemenliği süreci (ca. MÖ 600 - 509), Roma Cumhuriyet Dönemi (MÖ 509 - 27) ve de lulius Caesar ile Augustus'un askeri ve siyasi faaliyetleri, alt başlıklar şeklinde ele alınmaktadır. Augustus Döneminde Roma (457-465) başlıklı yirmi birinci bölümde, MÖ 27 - MS 14 yılları arasında Roma İmparatorluğu'na yön vermiş ve aynı zamanda da principatus (imparatorluk) rejiminin kurucusu olan Augustus ve faaliyetlerine yer verilmektedir. Başkentin Dışındaki italya (467-484) başıklı yirmi ikinci bölümde ise, Pompeii ve Ostia gibi önemli Roma yerleşimleri incelenmektedir. Neron'dan Hadrianus'a Roma (485-509) olarak adlandırılan yirmi üçüncü bölümde, MS I ile III. yüzyılın başları arasındaki zaman periyodunda Roma tahtına hükmeden imparatorlar ele alınmaktadır. Söz konusu imparatorlar incelenirken, lulius - Claudiuslar (MS 14-69); Üç Kısa Saltanat (MS 68-69); Flaviuslar (MS 69-96); Yüksek İmparatorluk (MS 96 - 193) ve de Severuslar (MS 193-235) alt başlıkları açılmakta ve her imparator detaylı olarak anlatılmaktadır.

Roma Eyalet Kentleri (511-536) yirmi dördüncü bölümdür. Burada, İtalya dışındaki eyaletlerdeki kentlerin İtalya'dakilere ne ölçüde benzediği ve ne ölçüde farklı olduğu konusu tartışmaya sunulmaktadır. Bu inceleme, Atina, Ephesos, Pergamon, Perge, Palmyra, Jeraş ve Leptis Magna kentleriyle başlamakta, Nimes, Londra ve Trier ile de devam etmektedir. Geç Antikçağdaki Dönüşümler (537-551) başılılı yirmi beşinci bölümde, Constantinus Dönemi'ndeki Roma, Kudüs ve Konstantinopolis kentleri ele alınmaktadır. Yazar, Büyük Constantinus Dönemi'nin, Antikçağın sonu, Ortaçağın başlangıcı, Akdeniz ve Yakındoğu'nun tarihindeyse yeni bir dönemin açılması anlamı- 
na geldiğini vurgulamaktadır. Akabinde, bu dönüşümü temsil eden bazı öğeleri, özellikle de Akdeniz Havzası'ndaki kentlerin değişen görünüş ve işlevleri üzerinde bir etkisi olan unsurları detaylı olarak aktarmaktadır. Bölümler bu şekilde sonlanmaktadır. Çalışmanın sonunda Kavramlar Sözlüğü (553-560) bulunmaktadır. Burada, kitabın içinde kullanılan kavramlar ve de terimler açıklanmaktadır. Daha sonraki kısım olan Ek Okumalar (561-568) kapsamında, eserin içeriğindeki konularla ilgili olarak daha detaylı bilgi sahibi olmak isteyen okurlar için kaynak listesi verilmektedir. Akabinde, Kaynakça (569-594), Görsel Kaynaklar (595-604) ve Dizin (605-613) kısımları ile kitap sona ermektedir. 